University of South Florida

DIGITAL COMMONS

Digital Commons @ University of

@ UNIVERSITY OF SOUTH FLORIDA

South Florida

School of Geosciences Faculty and Staff

Publications

School of Geosciences

$4-2020$

\title{
Modeling the Contribution of Poroelastic Deformation to Postseismic Geodetic Signals
}

\author{
Kimberly McCormack \\ University of Texas at Austin \\ Marc A. Hesse \\ University of Texas at Austin \\ Timothy H. Dixon \\ University of South Florida, thd@usf.edu \\ Rocco Malservisi \\ University of South Florida, rocco@usf.edu
}

Follow this and additional works at: https://digitalcommons.usf.edu/geo_facpub

Part of the Earth Sciences Commons

\section{Scholar Commons Citation}

McCormack, Kimberly; Hesse, Marc A.; Dixon, Timothy H.; and Malservisi, Rocco, "Modeling the Contribution of Poroelastic Deformation to Postseismic Geodetic Signals" (2020). School of Geosciences Faculty and Staff Publications. 2265.

https://digitalcommons.usf.edu/geo_facpub/2265

This Article is brought to you for free and open access by the School of Geosciences at Digital Commons @ University of South Florida. It has been accepted for inclusion in School of Geosciences Faculty and Staff Publications by an authorized administrator of Digital Commons @ University of South Florida. For more information, please contact digitalcommons@usf.edu. 


\section{Geophysical Research Letters}

\author{
RESEARCH LETTER \\ 10.1029/2020GL086945 \\ Key Points: \\ - For the Nicoya earthquake the \\ poroelastic deformation can \\ account for most of the postseismic \\ deformation within 7 days at some \\ stations \\ - For this earthquake, postseismic \\ geodetic signals can be either \\ amplified or muted by the \\ poroelastic response, depending on \\ location \\ - The poroelastic response to the \\ Nicoya earthquake may induce \\ error up to $40 \%$ in elastic-only \\ afterslip estimates
}

Supporting Information:

- Supporting Information S1

Correspondence to:

M. A. Hesse,

mhesse@jsg.utexas.edu

Citation:

McCormack, K., Hesse, M. A.,

Dixon, T. H., \& Malservisi, R. (2020).

Modeling the contribution of

poroelastic deformation to postseismic

geodetic signals. Geophysical

Research Letters, 47, e2020GL086945.

https://doi.org/10.1029/2020GL086945

Received 9 JAN 2020

Accepted 19 MAR 2020

Accepted article online 9 APR 2020

(C)2020. American Geophysical Union. All Rights Reserved.

\section{Modeling the Contribution of Poroelastic Deformation to Postseismic Geodetic Signals}

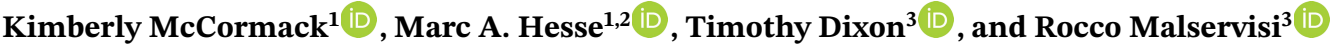 \\ ${ }^{1}$ Department of Geological Sciences, University of Texas at Austin, Austin, TX, USA, ${ }^{2}$ Oden Institute for Computational \\ Engineering and Science, University of Texas at Austin, TX, USA, ${ }^{3}$ School of Geosciences, University of South Florida, \\ Tampa, FL, USA
}

\begin{abstract}
To constrain the poroelastic component of postseismic deformation, we model the subsurface hydrologic response to the $M_{w} 7.6$ subduction zone earthquake that occurred on the plate interface beneath the Nicoya peninsula in Costa Rica on 5 September 2012. The model shows that poroelastic relaxation occurs on multiple time scales and the associated deformation can be up to $2 \mathrm{~cm}$ for the trench-perpendicular component. By modeling the time-dependent deformation associated with poroelastic relaxation, we can begin to remove its contribution from the observed geodetic signal. Inversions for after slip that ignore poroelastic deformation have errors of 10-20\% overall and up to 50\% locally. Poroelastic effects can both mute and amplify the inferred afterslip.
\end{abstract}

Plain Language Summary Large earthquakes can affect regional groundwater pressures. This sets up large-scale groundwater movements that in turn lead to observable surface deformation. Accounting for these deformations is important during interpretation of GPS signals after large earthquakes. These measurements are often used to infer ongoing deformation on the fault. We show that if these calculations do not account for deformation due to groundwater flow, this can lead to errors of up to $40 \%$.

\section{Introduction}

Following a large earthquake, surface deformation is influenced by a myriad of postseismic processes occurring on different spatial and temporal scales. These include continued slip on the fault plane (after-slip), a poroelastic response due to the movement of over-pressurized fluid, and viscoelastic relaxation of the lower crust and underlying mantle (Segall, 2010). Often, the only means of observing these phenomena are through geodetic measurements. Such tools measure the combined result of all these processes, which makes studying the effects of any single process difficult.To obtain accurate estimates of afterslip, it is necessary to remove the contributions of both poroelastic and viscoelastic relaxation. The particular timescales of response associated with each post-earthquake process can be challenging to determine from deformation observations alone. Mechanical models are therefore relied upon to predict the effect of one or more of these processes.

Poroelasticity and pore fluids have been studied for a wide range of subduction zone processes; as a mechanism for post-seismic stress transfer and triggering (Hughes et al., 2010) as well as fluid flow and heat transport (Cutillo et al., 2006), to constrain slow slip events offshore (Davis et al., 2015; Labonte et al., 2009), and to explain reductions in seismic velocity (Chaves \& Schwartz, 2016), among other phenomena.

Here we are interested in modeling the poroelastic component of postseismic deformation, which has the potential to be independently constrained by hydrologic measurements. Poroelasticity describes the behavior of fluid-saturated porous medium, capturing the relationship between deformation of the rock matrix and pore fluid pressure. The availability of additional data constraints, specifically for rock permeability and times series of well levels, makes poroelasticity a good candidate to remove its deformation effects from geodetic signals using mechanical models, prior to interpretation of other effects.

While some studies of postseismic surface deformation have evaluated poroelastic effects (Albano et al., 2017; Hu et al., 2014; Jonsson et al., 2003; Peltzer et al., 1998; Panuntun et al., 2018), none have explicitly 
evaluated to time-dependent three-dimensional behavior of poroelastic rebound and its effect on afterslip estimates. To best capture the spatial and temporal extent of the poroelastic response, high-rate well level data across the study area is needed. Alternatively, we can use models based on well-known physical parameters to get a first-order approximation of this response.

Geodetic measurements of surface deformation have captured changes in deformation rate in the hours, weeks, and years following a number of major earthquake (Beavan et al., 2012; Gunawan et al., 2014; Hu et al., 2014; Johanson et al., 2006; Malservisi et al., 2015). Separating out postseismic processes from one another is a key component in understanding where and how stress is transferred after large earthquakes (Hughes et al., 2010; Segall, 2010). After-slip can release large amounts of built up strain aseismically, and mapping the spatial and temporal patterns of after-slip is a key component in forecasting future seismic hazards (Dixon et al., 2014; Feng et al., 2012; Jiang et al., 2017; Voss et al., 2017).

Poroelastic deformation is thought to occur on timescales of days to weeks, whereas longer timescales on the order of months to years are associated with afterslip and viscous relaxation (Barbot \& Fialko, 2010; Helmstetter \& Shaw, 2009; Freed et al., 2017; Perfettini \& Avouac, 2004). However, postseismic poroelastic deformation can occur on multiple timescales that overlap with those currently linked to afterslip and viscous relaxation (Hughes et al., 2010; McCormack \& Hesse, 2018; Nespoli et al., 2018). Thus, attributing surface deformation to these different processes may be more complicated than previously thought. In particular, the poroelastic response can result in surface deformation signals on time scales that may be conflated with additional slip on the fault interface. Current geodetic inversions for after-slip generally do not account for the role of poroelasticity on postseismic deformation.

When poroelasticity has been considered either as a mechanism for coseismic well head changes or as a postseismic deformation mechanism, it is usually done so with linear elastic models (Fialko, 2004; Hu et al., 2014; Jonsson et al., 2003; Peltzer et al., 1998; Panuntun et al., 2018). In the case of calculating coseismic well head response due to static strain, the instantaneous volumetric strain produced by the earthquake is calculated with an undrained elastic model. These volumetric strains are converted into changes in a well head via Skempton's coefficient and compared with measured well observations. For studies that look at the surface deformation produced by poroelasticity, the elastic problem is typically solved with "undrained" and "drained" elastic parameters to find the instantaneous and fully-drained deformation states. The difference between the two is taken as the total poroelastic deformation. While this gives the net magnitude and direction of the poroelastic displacement, any complexity in between is missed, and the timescales of poroelastic deformation remain unknown. Determining these requires a transient poroelastic model and is the approach chosen here.

\subsection{Nicoya Earthquake}

Here we study the potential poroelastic contribution to afterslip of a megathrust earthquake and its effect on the inferred afterslip on the fault plane. We use the example of the 2012 Nicoya earthquake, because the favorable location of the GPS monitoring network, directly above the seismogenic zone, has led to detailed studies reconstructing both the coseismic slip and the afterslip (Hobbs et al., 2017; Malservisi et al., 2015; Protti et al., 2013; Yue et al., 2013). There is also significant postseismic surface deformation on timescales typically associated with poroelastic relaxation. Therefore, the 2012 Nicoya earthquake provides a suitable test case to study the potential effect of poroelastic relaxation on estimates of afterslip. While detailed data for the response of the well heads to the 2012 Nicoya earthquake is not available, other information, described below, provides first-order constraints for our model.

Seismicity patterns in Costa Rica reflect interactions of Caribbean, Nazca, and Cocos Plates. Recent large events along Nicoya and other parts of the trench include the $\mathrm{M}_{w} 7.01990$ Nicoya Gulf, $M_{w} 7.41983$ Gulfo Dulce, $M_{s} 7.01978$ Nicoya Peninsula, and $M_{s} 7.71950$ Nicoya Peninsula earthquakes (Feng et al., 2012; Norabuena, 2004; Protti et al., 2013).

During the 2012 Nicoya earthquake, 18 continuous stations were deployed on the Nicoya Peninsula. Time series of surface deformation recorded at GPS stations show considerable postseismic deformation in the days and months after the 2012 earthquake. Time-series of GPS station locations in the weeks to years after the 2012 earthquake indicate three distinct relaxation times of 7, 70, and 420 days (Malservisi et al., 2015). The shortest timescale is cautiously inferred to be associated with a poroelastic response to the 2012 earthquake. However, detailed modeling of the poroelastic relaxation shows a more complicated and prolonged 
(a) Instantaneous well head change

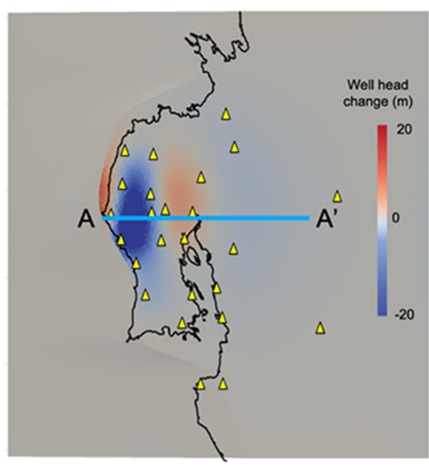

(b)

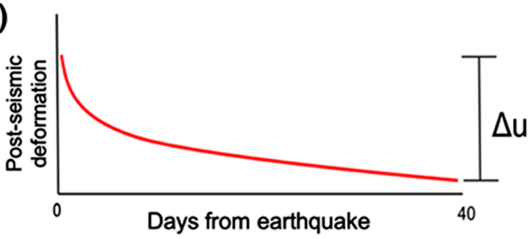

Cumulative trench-perpendicular deformation $(\Delta \mathrm{u})$
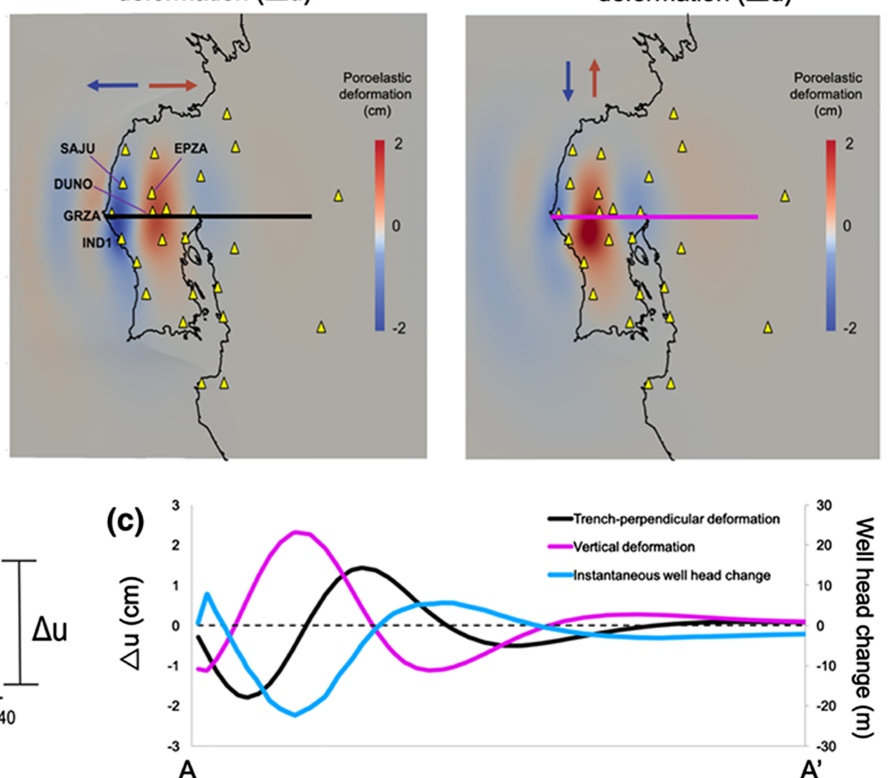

Figure 1. (a) Modeled surface well head response to the 2012 Nicoya earthquake with blue line showing a cross section plotted in (d). GPS stations are plotted as yellow triangles. (b) Modeled cumulative horizontal trench-perpendicular deformation $(\Delta u)$ for the 40 day period following the earthquake. Black line traces the cross section plotted in (d). (c) Modeled cumulative vertical deformation for the 40 day period following the earthquake. Magenta line traces the cross section plotted in (d). (d) Instantaneous well head and cumulative deformation for both trench-perpendicular and uplift components over cross section of the 3-D model - shown as A to A'. Colors of plotted lines correspond to colors of lines denoting cross section in upper panels.

poroelastic response (McCormack \& Hesse, 2018). Below we investigate its effect on the reconstruction of the afterslip.

\section{Model Setup}

To model the instantaneous and time-dependent poroelastic response to the earthquake, we use a fully coupled, linear poroelastic model developed in (McCormack \& Hesse, 2018) and summarized here. The model is initialized with the instantaneous undrained response to the 2012 Nicoya earthquake, where the slip of the earthquake is inferred from an elastic inversion of the coseismic surface displacements. This instantaneous undrained response determines the pattern of poroelastic deformation. For this model configuration, the inferred slip_-both coseismic and postseismic — is only for the overriding plate, and thus represents only about $50 \%$ of the total slip across the fault plane, assuming standard double-couple behavior.

The linear poroelastic theory developed by Biot provides a system of equations describing the coupling between pore fluid flow and rock deformation (Wang, 2000). The governing equations, combining the conservation of fluid mass for the evolution of pore fluid pressure, $p=p(\mathbf{x}, t)$, and total momentum conservation of the porous medium for the quasi-static solid displacement, $\mathbf{u}=\mathbf{u}(\mathbf{x}, t)$, in a domain, $\Omega$, over the time interval, $[0, T]$, are given by

$$
\begin{gathered}
\frac{d}{d t}\left(S_{\epsilon} p+\alpha \nabla \cdot \mathrm{u}\right)-\nabla \cdot\left(\frac{\kappa}{\mu} \nabla p\right)=0 \text { in } \Omega, \\
-\nabla \cdot(\sigma(\mathrm{u})-\alpha p \mathrm{I})=0 \text { in } \Omega,
\end{gathered}
$$

where $S_{\epsilon}$ is the specific storage, $\kappa(\mathbf{x})$ is the permeability, $\mu$ is the fluid viscosity, and $\alpha$ is the Biot-Willis parameter. In an elastic medium, the stress tensor, $\sigma$, is related to displacement as

$$
\boldsymbol{\sigma}(\mathrm{u})=G\left(\nabla \mathrm{u}+\nabla \mathrm{u}^{T}\right)+G(z) \frac{2 v}{1-2 v}(\nabla \cdot \mathrm{u}),
$$



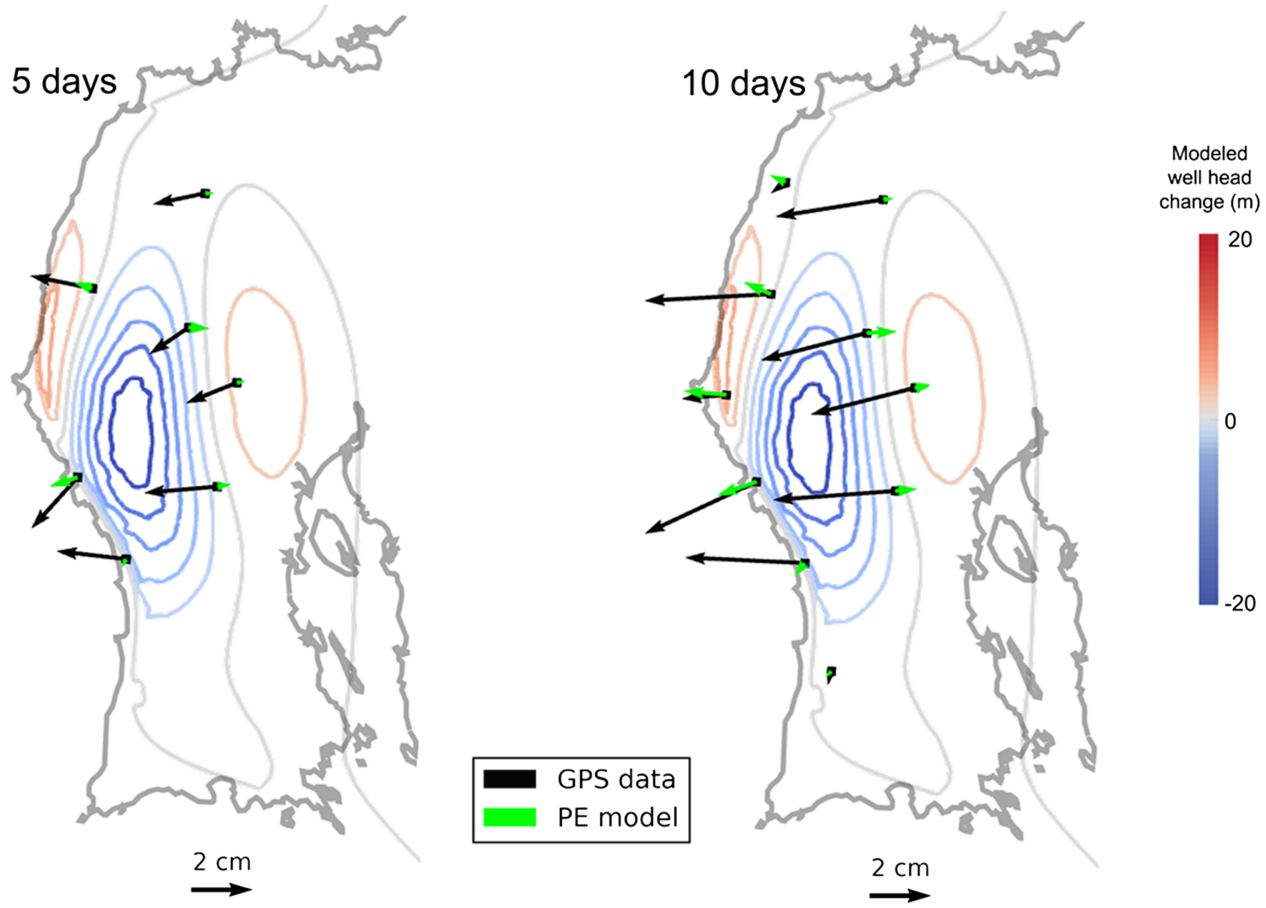

Figure 2. Comparison of modeled horizontal poroelastic (green vectors) and measured displacements (black vectors) for the 5 and 10 day windows following the earthquake. Initial near-surface head changes are shown as red-blue contours, where red indicates an increase in head (see also Figure 1a). Coastal contour shown in grey.

where $G(z)$ and $v$ are the elastic shear modulus and drained Poisson's ratio, respectively. The poroelastic Equation 1 requires six independent parameters. The Biot-Willis parameter $\alpha$ and the specific storage coefficient $S_{\epsilon}$ can be written in terms of the elastic parameters as

$$
\alpha=\frac{3\left(v_{u}-v\right)}{B\left(1+v_{u}\right)(1-2 v)}, \quad S_{\epsilon}=\frac{3 \alpha(1-2 v)(1-\alpha B)}{2 G B(1+v)},
$$

where $B$ is Skempton's pore pressure coefficient and $v$ and $v_{u}$ are the drained and undrained Poisson's ratios, respectively. Here we choose $B$ and $v_{u}$ as the primary parameters rather than $S_{\epsilon}$ and $\alpha$. This way the drained and undrained responses are described by $v, v_{u}$, and $G$; the coupling between fluid and solid is determined by $B$, and the duration of the poroelastic transient are described by $\kappa$ and $\mu$. In our model only $G$ and $\kappa$ vary spatially, and the other parameters are assumed to be uniform. All well heads discussed below and shown in Figures 1a and Figure 2 are computed from pore pressure changes using the relationship:

$$
\Delta h=\frac{\Delta p}{\rho g} .
$$

McCormack and Hesse (2018) give a detailed description of the parameter selection for the poroelastic model. The model domain in relation to the study area, initial slip condition, and model geometry are shown and described in Figure S1 in the Supplementary materials. The elastic parameters are based on previous seismic studies and vary only with depth, while the hydrological parameters are derived from the analysis of several hundred well test in the area and vary in all three dimensions of the model. The near-surface permeability values are interpolated from pump-test results (as shown in Figure S1b), and the permeability decay down the the residual permeability at depth is based on the model of Kuang and Jiao (2014). The resulting parameter values and references are listed in Table 1.

\section{Results}

The magnitude of surface deformation caused by earthquake-induced fluid flow can be significant. This section looks both at general trends in the poroelastic response and compares model results with GPS time series. 
Table 1

Table of chosen and interpolated parameter values for the numerical models

\begin{tabular}{lccccc}
\hline Parameter & Description & Model min & Model max & Comparison & Reference \\
\hline$G[\mathrm{MPa}]$ & Shear modulus & $2-6 \cdot 10^{4}$ & $2-6 \cdot 10^{4}$ & $2-6 \cdot 10^{4}$ & (Deshon et al., 2006) \\
$v$ & Drained Poisson's ratio & 0.3 & 0.25 & 0.27 & \\
$v_{u}$ & Undrained Poisson's ratio & 0.35 & 0.4 & 0.38 & \\
$B$ & Skempton's coefficient & 0.4 & 0.8 & 0.6 & \\
$\kappa_{S}\left[\mathrm{~m}^{2}\right]$ & Near-surface permeability & $10^{-(10-13)}$ & $10^{-(10-13)}$ & $10^{-(10-13)}$ & (SENARA; Becker \& Davis, 2004) \\
$\kappa_{r}\left[\mathrm{~m}^{2}\right]$ & Permeability at depth & $10^{-18}$ & $10^{-18}$ & $10^{-18}$ & \\
$\mu[\mathrm{MPa} \cdot \mathrm{s}]$ & $\quad$ Fluid viscosity & $10^{-9}$ & $10^{-9}$ & $10^{-9}$ & \\
\hline
\end{tabular}

Note. The min model and max model values are end-members of unconstrained values used to produce the minimum and maximum poroelastic response, respectively. The comparison model parameters are intermediate values that are used to produce the potential contribution to afterslip estimates in Figure 4.

\subsection{Patterns in Initial and Total Poroelastic Response}

Before investigating the 3-D results and their comparison with real GPS data, it is useful to look at the relationships between the earthquake-induced well head change and both the trench-perpendicular and vertical components of poroelastic deformation. Due to the predominantly dip-slip nature of the Nicoya event, the trench parallel component of postseismic deformation is small and is not discussed further here. However, the trench-parallel component may be important for events with more oblique slip.

Figure 1d shows that the vertical poroelastic deformation occurring within the first 40 days is almost a direct inverse of the initial head change, while the horizontal deformation is related to the gradient of the initial head change. These relationships can be understood as follows: Regions of well head drop are caused by coseismic dilation of the poroelastic medium. Fluids are drawn to the dilated regions and cause postseismic uplift, while compressed regions lose fluid and undergo postseismic subsidence. Regional maximums and minimums in coseismic head changes will see the largest gains/losses as the pore pressure equilibrates. Conversely, the horizontal poroelastic deformation at a given location is not controlled by mass change directly below it, but by how much mass (pore fluid) is moved from one side of the GPS station to the other. Thus, it is the highest gradients of earthquake-induced head changes that produce the largest horizontal displacements (Figure 2). Hence, even regions with small coseismic well head changes may experience significant horizontal poroelastic deformations as initial head gradients relax. Meanwhile, large vertical deformation is more directly related to the inverse of the coseismic head change. These relationships are consistent with those observed in other postseismic poroelastic studies (Albano et al., 2017; Nespoli et al., 2018)

The overall pattern of the horizontal postseismic poroelastic displacement, shown in Figure 1b, is in the opposite direction of the fluid flow during poroelastic relaxation. This is contrary to the behavior observed around pumping wells, where horizontal displacements are generally in the direction of fluid flow and hence towards minima in head (Wang, 2000). Here, the behavior is reversed because the flow into the regions of low head is not compensated by fluid extraction, which leads to a mass accumulation and associated expansion.

It is important to note that these relationships are only valid for relatively short time scales. Once the local maxima/minima begin to equilibrate and a larger-scale flow pattern becomes dominant, the relationships of the deformation to the initial head change are muted and/or lost (McCormack \& Hesse, 2018).

\subsection{Relationship to GPS Timeseries}

The goal of these models is not to try to match the observed surface deformation data, but rather to understand and quantify the amount of surface deformation produced by the poroelastic processes and how such deformation may interact with, and be misinterpreted as, afterslip.

In the three-dimensional model, the small width to depth ratio of the Nicoya rupture leads to a head change distribution comprising of multiple trench-parallel ridges of positive and negative head changes, Figure 1a shows the co-seismic near surface head change produced by the earthquake. There are no GPS stations located near a maximum or minimum in coseismic head change, so that they do not record the largest vertical poroelastic relaxation. Due to this and the significant noise in vertical GPS component, we focus our comparison below on the horizontal trench perpendicular component of postseismic deformation. 

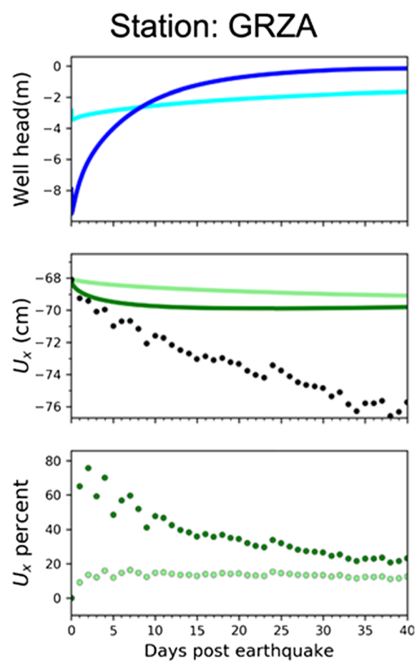

Figure 3. Transient postseismic poroelastic behavior at selected GPS station locations for a range of model parameters Top row shows the modeled well head response at the GPS station location. Green panels show the comparison of modeled and measured timeseries for the trench-ward component of deformation, both in terms of postseismic displacement and the percentage of the data that can be explained by the model. For comparison with more noisy vertical displacements see Figure S1.

The observed postseismic displacement is towards the trench (Figure 2). The modeled poroelastic deformation is in the opposite direction of the instantaneous head gradient (Figure 1b) and hence predominantly trench perpendicular. However, these displacements may point in more than one direction, so that modeled poroelastic relaxation may both enhance and subdue postseismic deformation. Near the coast, modeled and measured deformation point in the same direction, but inland, they point in opposite directions. Modeled poroelastic relaxation produces displacements on the order of $20 \%$ of the observed postseismic displacements in the first 5 days.

Figure 3 shows the transient modeled and observed trench-perpendicular deformation time series at three different GPS stations. The stations plotted are selected to illustrate the range of responses and are labeled in Figure 1b. The top row shows the range of the modeled transient well head response. The middle row compares the observed trench-ward postseismic displacement with the range of modeled poroelastic relaxation. The bottom row shows the percentage of the postseismic displacement explained by the poroelastic model. Positive percentages mean the data and the model are moving in the same direction, while negative percentages mean the data and model are moving in opposite directions. Here we use percentage instead of the correlation coefficient because the model is deterministic and hence does not have a variance. In the horizontal displacements, we see three types of relationships between the poroelastic model and the measured displacement. The first is when the poroelastic model follows the trend of the data and makes up some positive percentage of the data. We see this in Figure 3 for station GRZA (left column). The second is when the poroelastic displacement moves in the opposite direction of the data, such as at station EPZA (middle column). In the third case, such as at station DUNO (right column), the model follows the data for a short while, and then they diverge. Hence, the modeled poroelastic deformation does not have a straightforward relationship with total measured postseismic deformation.

We note that all modeled well heads in Figure 3 show rapid declines within a few days to weeks, followed by slow recoveries over several weeks to months. These two timescales arise because the near surface coseismic head change has two horizontal wavelengths (Figure 1a): the short-wavelength large-amplitude perturbation on the Nicoya peninsula that decays quickly and a larger regional perturbation that decays more slowly. In both cases the flow is largely confined to the high permeability near surface layer (McCormack \& Hesse, 2018).

\subsection{Effect on Afterslip Estimates}

The poroelastic response creates surface deformation that may be misinterpreted as afterslip. As a result, it is important to correct not only for the total amount of poroelastic deformation, but also for the poroelastic 

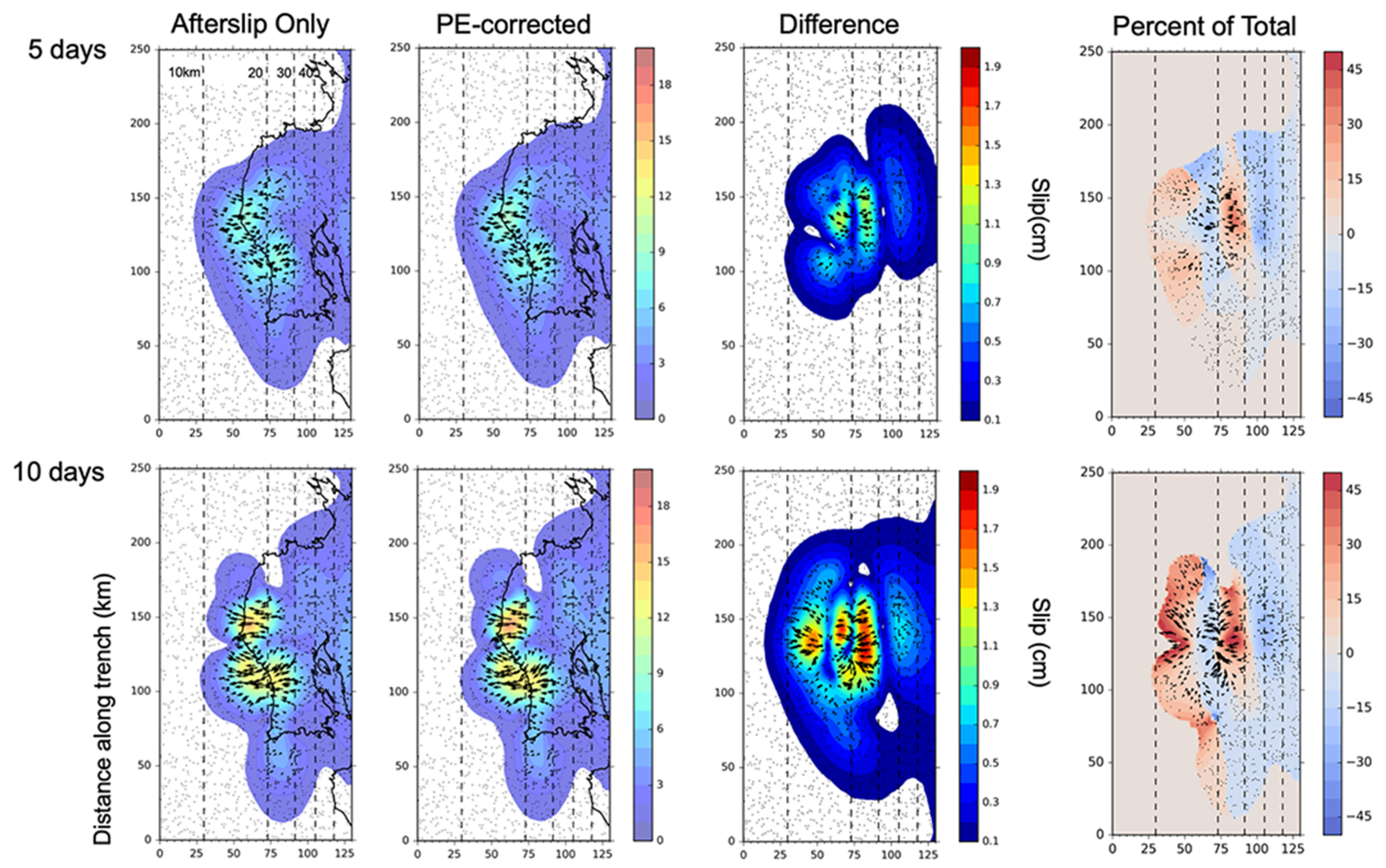

Figure 4. Afterslip estimates produced by inverting the postseismic surface deformation both with and without poroelastic behavior. Time windows of 5 and 10 days of the earthquake were used. The difference column shows the pattern and magnitude of "phantom" afterslip produced by not accounting for poroelasticity. The far-right column shows the percent of the afterslip-only solution that can accounted for by poroelasticity. Positive (red) percentages indict where afterslip is overestimated while negative (blue) regions is where afterslip is underestimated. Labeled dashed lines represent contours of the subduction interface.

deformation at each point in time after an earthquake. Differencing the modeled time-series of poroelastic deformation and measured total surface deformation will produce time series of surface deformation that are corrected for poroelasticity. Once the poroelasticity is corrected for in the geodetic time series, it is possible to re-evaluate the corrected deformation field for afterslip and viscoelastic deformation after an earthquake. In the time series plotted and discussed in section 3.2, not taking into account the poroelastic deformation would result in the afterslip being overestimated in some regions and underestimated in others. It is also worth noting that, for the case of the 2012 Nicoya earthquake studied here, there are many GPS stations (more than half) that are predicted to experience little-to-no post-seismic poroelastic deformation. It is important to predict both where poroelastic deformation will and will not make up any significant portion of the measured signal.

Figure 4 shows the results of inverting the observed postseismic deformation as afterslip for two cases: (1) all observed surface deformation is assumed to be elastic and directly resulting from afterslip; (2) The modeled poroelastic deformation is removed and the remainder is inverted as afterslip. The poroelastic model parameters used here were chosen to produce a moderate poroelastic response between the minimum and maximum scenarios shown in Figure 3. For comparison to previously published estimates of afterslip for the 2012 Nicoya earthquake (Hobbs et al., 2017; Malservisi et al., 2015), refer to Figure S2.

We see in Figure 4 that the afterslip estimates look very similar whether or not poroelastic effects are accounted. Thus, for this particular event, taking into account poroelasticity does not fundamentally change the character of the inferred afterslip. However, the difference column of Figure 4 shows the amount of "phantom" afterslip generated on just the head wall of the subduction interface by ignoring poroelastic effects. Overall, for the 2012 Nicoya earthquake studied here, the expected general contribution of poroelastic deformation over the first several weeks is on the order of $+/-10$ to $20 \%$ of the total observed deformation, 
and up to $+/-50 \%$ locally. This contribution could potentially be higher for shallower events and those that produce relatively smaller amounts of afterslip.

\section{Discussion}

The poroelastic contribution to the postseismic deformation signal can be significant and may be an important process to consider when parsing out the postseismic geodetic signal into after-slip, viscoelastic, and poroelastic relaxation. This is the first time the three-dimensional transient poroelastic response to a megathrust earthquake has been modeled and compared to GPS time series. While the postseismic poroelastic response is more complex than typically thought, it is the only process that can be constrained independently. Therefore, well head measurements are an important complimentary dataset for studies of post-seismic deformation.

A promising example to study the postseismic poroelastic response is the $M_{w}$ 7.1 Darfield earthquake that led to significant, widely recorded head responses on both short (days to weeks) and longer (up to a year) timescales (Cox et al., 2012). Similarly, offshore measurements of fluid flux and head in Circulation Obviation Retrofit Kit (CORK) boreholes and other ocean-bottom observatories provide constraints on subduction zone systems (Labonte et al., 2009).

Studying earthquake induced poroelastic relaxation also provides new insights into aquifer mechanics, because the response differs significantly from the more typical well-induced deformations (Wang, 2000). Poroelastic deformation is either due to pressure gradients in the fluid or to expansion/contraction of the matrix due to pore pressure changes. In flows driven by injection/extraction at wells, deformation is dominated by the pressure gradient. During postseismic poroelastic relaxation the deformation is dominated by changes in fluid storage. This leads to a reversal in the direction of lateral deformation, which is up-gradient during postseismic poroelastic relaxation (Figure 2).

Finally, we note that the limitations of the model, including the assumption of static permeability and the appropriate surface boundary condition, are discussed in detail in McCormack and Hesse (2018).

\section{Conclusion}

Acknowledgments

K.A.M. was supported by the National Science Foundation Graduate Research Fellowship under Grant DGE-1110007. M.A.H. was supported by NSF Grant CBET CDS\&E-1508713. T.H.D was supported by NSF Grant EAR-1835947. This work has benefited from the mathematical and computational expertise of Omar Ghattas and Umberto Villa at the Oden Institute for Computational Engineering and Science at the University of Texas at Austin. Well data was provided by Carlos Romero at SENARA (National Service of Groundwater, Irrigation and Drainage in Costa Rica).

The models used here were built using both FEniCS (Alnæs et al., 2014; Logg \& Wells, 2010; Logg et al., 2012) and Firedrake (Luporini et al., 2017; Rathgeber et al., 2016) - both collection of open source software components directed at the automated solution of differential equations by finite element method (Balay et al., 2017b, 2017a). Both 2-D and 3-D meshes were built using GMSH software (Geuzaine \& Remacle, 2009). The specific data, scripts, and meshes along with instructions for downloading and running the models used here are hosted and archived (https://github. com/kamccormack/EQporoelasticity).
Here we use transient three-dimensional poroelastic models to investigate the effect of poroelastic relaxation on the interpretation of post-seismic deformation of the $M_{w} 7.6$ earthquake on the Nicoya peninsula, Costa Rica. The model shows that poroelastic relaxation occurs over multiple timescales and can either mute or amplify postseismic geodetic signals. The magnitude of the relaxation can be up to $2 \mathrm{~cm}$ in the first 40 days and can account for most of the observed deformation at some stations in the first week. If the poroelastic contribution is not subtracted from elastic inversions of afterslip, it may introduce errors of approximately $+/-10-20 \%$ of the total observed deformation and account for up to $+/-50 \%$ locally.

\section{References}

Albano, M., Barba, S., Solaro, G., Pepe, A., Bignami, C., Moro, M., \& Stramondo, S. (2017). Aftershocks, groundwater changes and postseismic ground displacements related to pore pressure gradients: Insights from the 2012 Emilia-Romagna earthquake. Journal of Geophysical Research: Solid Earth, 122, 5622-5638. https://doi.org/10.1002/2017JB014009

Alnæs, M. S., Logg, A., Ølgaard, K. B., Rognes, M. E., \& Wells, G. N. (2014). Unified Form Language: A domain-specific language for weak formulations of partial differential equations. ACM Transactions on Mathematical Software, 40(2), 9. https://doi.org/10.1145/2566630

Balay, S., Abhyankar, S., Adams, M. F., Brown, J., Brune, P., Buschelman, K., \& Zhang, H. (2017a). PETSc Users Manual. ANL-95/11 Revision 3.8, Argonne National Laboratory, https://www.mcs.anl.gov/petsc

Balay, S., Abhyankar, S., Adams, M. F., Brown, J., Brune, P., Buschelman, K., \& Zhang, H. (2017b). PETSc Web page, https://www.mcs.anl. gov/petsc.

Barbot, S., \& Fialko, Y. (2010). A unified continuum representation of post-seismic relaxation mechanisms: Semi-analytic models of afterslip, poroelastic rebound and viscoelastic flow. Geophysical Journal International, 182(3), 1124-1140. https://doi.org/10.1111/j. 1365-246X.2010.04678.X

Beavan, J., Motagh, M., Fielding, E. J., Donnelly, N., \& Collett, D. (2012). Fault slip models of the 2010-2011 Canterbury, New Zealand, earthquakes from geodetic data and observations of postseismic ground deformation. New Zealand Journal of Geology and Geophysics, 55(January 2015), 207-221. https://doi.org/10.1080/00288306.2012.697472

Becker, K. \& Davis, E. E. (2004). In situ determinations of the permeability of the igneous oceanic crust. Hydrogeology of the oceanic lithosphere (pp. 189-224). Cambridge, UK: Cambridge University Press.

Chaves, E. J., \& Schwartz, S. Y. (2016). Monitoring transient changes within overpressured regions of subduction zones using ambient seismic noise. Science Advances, 2(1), e1501289. https://doi.org/10.1126/sciadv.1501289

Cox, S., Rutter, H., Sims, a., Manga, M., Weir, J., Ezzy, T., \& Scott, D. (2012). 7.1 Darfield (Canterbury) earthquake, 4 September 2010, New Zealand. New Zealand Journal of Geology and Geophysics, 55(January 2015), 231-247. https://doi.org/10.1080/00288306.2012.680474 
Cutillo, P. A., Ge, S., \& Screaton, E. J. (2006). Hydrodynamic response of subduction zones to seismic activity: A case study for the Costa Rica margin. Tectonophysics, 426, 167-187. https://doi.org/10.1016/j.tecto.2006.02.017

Davis, E. E., Villinger, H., \& Sun, T. (2015). Slow and delayed deformation and uplift of the outermost subduction prism following ETS and seismogenic slip events beneath Nicoya Peninsula, Costa Rica. Earth and Planetary Science Letters, 410, 117-127. https://doi.org/ 10.1016/j.epsl.2014.11.015

DeShon, H. R., Schwartz, S. Y., Newman, A. V., González, V., Protti, M., Dorman, L. M., et al. (2006). Seismogenic zone structure beneath the Nicoya Peninsula, Costa Rica, from three-dimensionallocal earthquake P- and S-wave tomography. Geophysical Journal International, 164(1), 109-124.

Dixon, T. H., Jiang, Y., Malservisi, R., McCaffrey, R., Voss, N., Protti, M., \& Gonzalez, V. (2014). Earthquake and tsunami forecasts: Relation of slow slip events to subsequent earthquake rupture. Proceedings of the National Academy of Sciences, 111(48), 17,039-17,044. https:// doi.org/10.1073/pnas.1412299111

Feng, L., Newman, A. V., Protti, M., González, V., Jiang, Y., \& Dixon, T. H. (2012). Active deformation near the Nicoya Peninsula, northwestern Costa Rica, between 1996 and 2010: Interseismic megathrust coupling. Journal of Geophysical Research, 117, B06407. https://doi.org/10.1029/2012JB009230

Fialko, Y. (2004). Evidence of fluid-filled upper crust from observations of postseismic deformation due to the 19927.3 Landers earthquake. Journal of Geophysical Research, 109, B08401. https://doi.org/10.1029/2004JB002985

Freed, A. M., Hashima, A., Becker, T. W., Okaya, D. A., Sato, H., \& Hatanaka, Y. (2017). Resolving depth-dependent subduction zone viscosity and afterslip from postseismic displacements following the 2011 Tohoku-oki, Japan earthquake. Earth and Planetary Science Letters, 459, 279-290. https://doi.org/10.1016/j.epsl.2016.11.040

Geuzaine, C., \& Remacle, J. F. (2009). Gmsh: A 3-D finite element mesh generator with built-in pre-and post-processing facilities. International Journal for Numerical Methods in Engineering, 79(11), 1309-1331.

Gunawan, E., Sagiya, T., Ito, T., Kimata, F., Tabei, T., Ohta, Y., \& Sugiyanto, D. (2014). A comprehensive model of postseismic deformation of the 2004 Sumatra-Andaman earthquake deduced from GPS observations in northern Sumatra. Journal of Asian Earth Sciences, 88, 218-229. https://doi.org/10.1016/j.jseaes.2014.03.016

Helmstetter, A., \& Shaw, B. E. (2009). Afterslip and aftershocks in the rate-and-state friction law. Journal of Geophysical Research, 114, B01308. https://doi.org/10.1029/2007JB005077

Hobbs, T., Kyriakopoulos, C., Newman, A., Protti, M., \& Yao, D. (2017). Large and primarily updip afterslip following the $2012 \mathrm{M}$ w 7.6 Nicoya, Costa Rica earthquake: Afterslip from 2012 Nicoya Earthquake. Journal of Geophysical Research: Solid Earth, 122, 5712-5728. https://doi.org/10.1002/2017JB014035

Hu, Y., Bürgmann, R., Freymueller, J. T., Banerjee, P., \& Wang, K. (2014). Contributions of poroelastic rebound and a weak volcanic arc to the postseismic deformation of the 2011 Tohoku earthquake. Earth, Planets and Space, 66(1), 106. https://doi.org/10.1186/ 1880-5981-66-106

Hughes, K. L. H., Masterlark, T., \& Mooney, W. D. (2010). Poroelastic stress-triggering of the 2005 M8.7 Nias earthquake by the 2004 M9.2 Sumatra-Andaman earthquake. Earth and Planetary Science Letters, 293(3-4), 289-299. https://doi.org/10.1016/j.epsl.2010.02.043

Jiang, Y., Liu, Z., Davis, E. E., Schwartz, S. Y., Dixon, T. H., Voss, N., \& Protti, M. (2017). Strain release at the trench during shallow slow slip: The example of Nicoya Peninsula, Costa Rica. Geophysical Research Letters, 44, 4846-4854. https://doi.org/10.1002/2017GL072803

Johanson, I. A., Fielding, E. J., Rolandone, F., \& Bürgmann, R. (2006). Coseismic and postseismic slip of the 2004 Parkfield earthquake from space-geodetic data. Bulletin of the Seismological Society of America, 96(4 B), 269-282. https://doi.org/10.1785/0120050818

Jonsson, S., Segall, P., Pedersen, R., \& Grimur, B. (2003). Post-earthquake ground movements correlated to pore-pressure transients. Nature, 424(July), 179-183. https://doi.org/10.1038/nature01758.1.

Kuang, X., \& Jiao, J. J. (2014). An integrated permeability-depth model for Earth's crust. Geophysical Research Letters, 41, 7539-7545. https:// doi.org/10.1002/2014GL061999

Labonte, A. L., Brown, K. M., \& Fialko, Y. (2009). Hydrologic detection and finite element modeling of a slow slip event in the Costa Rica prism toe. Journal of Geophysical Research, 114, B00A02. https://doi.org/10.1029/2008JB005806

Logg, A., Mardal, K. A., \& Wells, G. N. (2012). Automated solution of differential equations by the finite element method: Springer. https:// doi.org/10.1007/978-3-642-23099-8

Logg, A., \& Wells, G. N. (2010). DOLFIN: Automated finite element computing. ACM Transactions on Mathematical Software, 37(2), 20. https://doi.org/10.1145/1731022.1731030

Luporini, F., Ham, D. A., \& Kelly, P. H. J. (2017). An algorithm for the optimization of finite element integration loops. ACM Transactions on Mathematical Software, 44, 3:1-3:26. https://doi.org/10.1145/3054944

Malservisi, R., Schwartz, S. Y., Voss, N., Protti, M., Gonzalez, V., Dixon, T. H., \& Voyenko, D. (2015). Multiscale postseismic behavior on a megathrust: The 2012 Nicoya earthquake, Costa Rica. Geochemistry, Geophysics, Geosystems, 16, 1848-1864. https://doi.org/10.1002/ 2015GC005794

McCormack, K. A., \& Hesse, M. A. (2018). Modeling the poroelastic response to megathrust earthquakes: A look at the $2012 M_{w} 7.6$ Costa Rican event. Advances in Water Resources, 114, 236-248. https://doi.org/10.1016/j.advwatres.2018.02.014

Nespoli, M., Belardinelli, M. E., Gualandi, A., Serpelloni, E., \& Bonafede, M. (2018). Poroelasticity and fluid flow modeling for the 2012 Emilia-Romagna earthquakes: Hints from GPS and InSAR data. Geofluids, 2018, 4,160,570.

Norabuena, E. (2004). Geodetic and seismic constraints on some seismogenic zone processes in Costa Rica. Journal of Geophysical Research, 109, B11403. https://doi.org/10.1029/2003JB002931

Panuntun, H., Miyazaki, S., Fukuda, Y., \& Orihara, Y. (2018). Probing the Poisson's ratio of poroelastic rebound following the 2011 Mw 9.0 Tohoku earthquake. Geophysical Journal International, 215(3), 2206-2221. https://doi.org/10.1093/gii/ggy403

Peltzer, G., Rosen, P., Rogez, F., \& Hudnut, K. (1998). Poroelastic rebound along the Landers 1992 earthquake surface rupture. Journal of Geophysical Research, 103(98), 30,131-30,145. https://doi.org/10.1029/98JB02302

Perfettini, H., \& Avouac, J. P. (2004). Postseismic relaxation driven by brittle creep: A possible mechanism to reconcile geodetic measurements and the decay rate of aftershocks, application to the Chi-Chi earthquake, Taiwan. Journal of Geophysical Research, 109, B02304. https://doi.org/10.1029/2003JB002488

Protti, M., González, V., Newman, A. V., Dixon, T. H., Schwartz, S. Y., Marshall, J. S., \& Owen, S. E. (2013). Nicoya earthquake rupture anticipated by geodetic measurement of the locked plate interface. Nature Geoscience, 7(2), 117-121. https://doi.org/10.1038/ngeo2038

Rathgeber, F., Ham, D. A., Mitchell, L., Lange, M., Luporini, F., McRae, A. T. T., \& Kelly, P. H. J. (2016). Firedrake: Automating the finite element method by composing abstractions. ACM Transactions on Mathematical Software, 43(3), 24:1-24:27. https://doi.org/10. $1145 / 2998441$

Segall, P. (2010). Earthquake and volcano deformation. Princeton: Princeton University Press. 
Voss, N. K., Malservisi, R., Dixon, T. H., \& Protti, M. (2017). Slow slip events in the early part of the earthquake cycle. Journal of Geophysical Research: Solid Earth, 122, 6773-6786. https://doi.org/10.1002/2016JB013741

Wang, H. (2000). Theory of linear poroelasticity with applications to geomechanics and hydrogeology. Princeton, NJ: Princeton University Press.

Yue, H., Lay, T., Schwartz, S. Y., Rivera, L., Protti, M., Dixon, T. H., \& Newman, A. V. (2013). The 5 September 2012 Nicoya, Costa Rica Mw 7.6 earthquake rupture process from joint inversion of high-rate GPS, strong-motion, and teleseismic P wave data and its relationship to adjacent plate boundary interface properties. Journal of Geophysical Research: Solid Earth, 118, 5453-5466. https://doi.org/10.1002/ jgrb.50379 